\title{
Positive Allosteric Modulator of mGluR4 PHCCC Exhibits Proconvulsant Action in Three Models of Epileptic Seizures in Immature Rats
}

\author{
E. SZCZUROWSKA ${ }^{1}$, P. MAREŠ ${ }^{1}$ \\ ${ }^{1}$ Department of Developmental Epileptology, Institute of Physiology, Academy of Sciences of the \\ Czech Republic, Prague, Czech Republic
}

Received February 13, 2012

Accepted June 26, 2012

On-line October 25, 2012

\section{Summary}

The activation of metabotropic glutamate receptors subtype 4 (mGluR4) potentiates models of absence seizures in adult rats. These seizures are age-dependent, but data concerning the role of mGluR4 in immature brain is insufficient. N-phenyl-7(hydroxyimino)cyclopropa[b]chromen-1acarboxamide (PHCCC), which is a positive allosteric modulator of these receptors, was used in three different models of seizures in immature rats: 1) convulsions induced by high doses of pentetrazol (PTZ; a model of generalised tonic-clonic seizures); 2) rhythmic electroencephalographic (EEG) activity induced by low doses of PTZ (a model of absence seizures); and 3) electrically elicited cortical afterdischarges (ADs, a model of myoclonic seizures). We administered four doses of PHCCC $(1,3,10$ and $20 \mathrm{mg} / \mathrm{kg})$ in PTZ-induced convulsions and two doses ( 3 and $10 \mathrm{mg} / \mathrm{kg}$ ) in the two electrophysiological models of freely moving rats with implanted electrodes. Every dose and age group consisted from 8 to 10 rats. PTZ-elicited convulsions were not significantly influenced by PHCCC. In contrast, PHCCC potentiated the effect of a subconvulsant dose (60 mg/kg) of PTZ. The $10-\mathrm{mg} / \mathrm{kg}$ dose of PHCCC significantly prolonged the duration of PTZ-induced rhythmic activity episodes and shortened the intervals between individual episodes in 25-day-old rats (P25). In contrast, this potentiation was not seen in P18 rats. Cortical ADs were significantly prolonged with repeated stimulations by both doses of PHCCC in P12 and P18 animals. P25 rats exhibited only slightly longer $A D$ durations. In conclusion, we did not find any anticonvulsant effect of PHCCC. On the contrary, proconvulsant action was demonstrated in all three models in immature rats.

\section{Key words}

Metabotropic glutamate receptor 4 - Epileptic seizures • Rat • Ontogeny

\section{Corresponding author}

P. Mareš, Department of Developmental Epileptology, Institute of Physiology, Academy of Sciences CR, Vídeňská 1083, CZ-14220 Prague 4, Czech Republic. Fax: +420 24106 2488. E-mail: maresp@biomed.cas.cz

\section{Introduction}

Glutamatergic neurotransmission plays an essential role in controlling brain function integration. In addition, it is a critical factor during early brain development (Catania et al. 1994, Conn and Pin 1997, Sarichelou et al. 2008). Among eight subtypes of metabotropic glutamate receptors (mGluR), subtype 4 (mGluR4) was found to be involved in pathogenesis of many disorders including anxiety (Stachowicz et al. 2006, Lavreysen and Dautzenberg 2008), depression (Cryan et al. 2003, Kogo et al. 2004, Kłak et al. 2007), neuropathic pain (Lavreysen and Dautzenberg 2008), Parkinson's disease (Lavreysen and Dautzenberg 2008, Hopkins et al. 2009) and several types of epilepsies (Snead et al. 2000, Chen et al. 2005, Marino et al. 2005, Wang et al. 2005, Pitsch et al. 2007). Therefore, drugs that modulate mGluR4 activity could represent viable pharmacological treatments for these diseases (Marino et al. 2005).

PHCCC (N-phenyl-7-(hydroxyimino)cyclopropa 
[b]chromen-1acarboxamide), a positive allosteric modulator of mGluR4, augmented in vivo genetic and pharmacological models of absence seizures in rats (Ngomba et al. 2008). In fact, mGluR4 is highly presynaptically expressed in thalamocortical neurons and fibres projecting from the striatum to the external globus pallidus. mGluR4 also regulates glutamate and GABA release in the reticular thalamic nucleus (RTN), as well as in the basal ganglia motor circuit. GABAergic neurons in the RTN synchronise physiological firing of interconnected glutamatergic thalamic relay cells and neocortical pyramidal neurons. These neurons are also responsible for pathological oscillations, such as bilaterally synchronised spike-and-wave discharges in thalamo-cortical circuitry. Thus, the RTN is involved in the pathogenesis of absence seizures (Snead et al. 2000, Wang et al. 2005). Transgenic mice that lack the receptor $\left(\mathrm{mGluR}^{-/-}\right)$are resistant to absence-like seizures induced by low doses of the GABA-A receptor antagonist pentetrazol (PTZ) (Snead et al. 2000, Wang et al. 2005, Ngomba et al. 2008). Data supporting a role for mGluR4 in other types of epileptic seizures are controversial (Lie et al. 2000, Corti et al. 2002, Chen et al. 2005, Lavreysen and Dautzenberg 2008).

The action of drugs in models of absences and other types of epileptic seizures is often opposite (GABA-B receptor antagonist - Vergnes et al. 1997, ethosuximide - Mareš 1998); therefore, we expected an anticonvulsant action of PHCCC in convulsive seizures. In general, activation of presynaptically-localised mGluRIII receptors inhibits glutamate release, and this inhibitory effect might be used to suppress convulsive epileptic seizures.

Absence seizures are age-dependent; they cannot appear before a certain level of maturation is achieved (Snead et al. 2000). A developmental study demonstrated a moderate presence of mGluR4 mRNA in the thalamus and low mGluR4 expression in other brain structures at birth. The signal increases slightly in the thalamus, striatum and neocortex during maturation but is dramatically upregulated in the cerebellum (Catania et al. 1994). Because no studies have investigated a possible effect of mGluR4 on epileptic seizures in developing animals, we decided to study the action of PHCCC in immature rats using three different seizure models. Animal ages were chosen to mimic developmental stages that are comparable with human brain development. Rats that are 12, 18 and 25 days old roughly correspond to human infants and young children (Gottlieb et al. 1977); seizure susceptibility is increased during these periods of intensive developmental change (Haas et al. 1990, Mareš et al. 2002). We began with a simple model of motor seizures induced by subcutaneously administered pentetrazol (PTZ). An appropriate dose of PTZ elicits two types of convulsive seizures: minimal clonic seizures generated in the basal forebrain of rats older than 17 days and generalised tonic-clonic seizures originating in the brainstem of all age groups (Browning and Nelson 1986). We also employed two electrophysiological models: spike-and-wave episodes induced by low systemic doses of PTZ (generated in cortico-thalamo-cortical circuits) and epileptic afterdischarges induced by low-frequency cortical stimulation (also generated in cortico-thalamocortical pathway but with a spread of seizure activity into the motor system). All three models are routinely used in our laboratory, and normative developmental data are at our disposal (Velíšek et al. 1992, Mareš 1998, Mareš et al. 2002, Szczurowska and Mareš 2009).

\section{Methods}

Animals

The experiments were carried out in male Wistar rat pups that were bred in-house. Animals were housed under standard conditions (food and water ad libitum, $12: 12 \mathrm{~h}$ light:dark cycle, lights on at 6 a.m., temperature $22 \pm 1^{\circ} \mathrm{C}$ ). The day of birth was counted as zero, and all litters were formed by eight male pups. Rat pups were taken from their mothers just before testing or surgery. Immature rat pup (up to $\mathrm{P} 18$ ) body temperature was maintained by an electrical heating pad $\left(34{ }^{\circ} \mathrm{C}\right.$ to mimic the nest temperature) during the whole experiment. All experiments were approved by the Animal Care and Use Committee of the Institute of Physiology of the Academy of Sciences of the Czech Republic and were conducted in agreement with the Animal Protection Law of the Czech Republic, which is fully compatible with European Community Council directives 86/609/EEC.

\section{Drugs}

PTZ (Sigma, St. Louis, MO) was dissolved in water immediately before the experiment. Concentrations used were 30 or $50 \mathrm{mg} / \mathrm{ml}$ for Experiment 1 and $20 \mathrm{mg} / \mathrm{ml}$ for Experiment 2. PHCCC (Ascent, UK) was freshly dissolved in $50 \%$ dimethylsulfoxide (DMSO, Sigma) for a final concentration of $10 \mathrm{mg} / \mathrm{ml}$. Doses of 3 and $10 \mathrm{mg} / \mathrm{kg}$ were chosen according to Ngomba's experiments (Ngomba et al. 2008), lower and higher 
doses (1 and $20 \mathrm{mg} / \mathrm{kg}$ ) were added in the introductory simplest experiment - PTZ-induced convulsions - to have results with a broader extent of doses.

\section{PTZ-induced convulsions}

Four age groups were studied: 7-, 12-, 18- and 25-day-old rats. PTZ (100 mg/kg) was administered subcutaneously to animals $30 \mathrm{~min}$ after pretreatment with PHCCC in doses of $1,3,10$ and $20 \mathrm{mg} / \mathrm{kg}$ given intraperitoneally (i.p.). Rats were observed in isolation for $30 \mathrm{~min}$ after PTZ injection, this interval was chosen on the basis of Ngomba's data (Ngomba et al. 2008). The incidence, pattern (minimal clonic seizures and generalised tonic-clonic seizures) and latencies of convulsions were registered. An additional series of experiments was performed in 25-day-old animals to separate a possible effect of PHCCC on minimal clonic seizures. The $60-\mathrm{mg} / \mathrm{kg}$ dose induced only minimal seizures in a subset of naïve rats, and generalised tonicclonic seizures were never observed. Therefore this dose is also suitable to test possible proconvulsant actions.

Pentetrazol-induced absence-like seizures (PTZ-induced rhythmic EEG activity)

This experiment was performed only in 18- and 25-day-old rats because younger animals are not able to generate episodes of spike-and-wave rhythm. Four flat, silver recording electrodes were implanted epidurally while the animals were under ether anesthesia. Appropriate placement coordinates for immature rats were determined by recalculating bregma-lambda distances from adult animals. Electrodes were placed bilaterally over the left and right sensorimotor (AP 0 , L $2 \mathrm{~mm}$ ) and visual cortices (AP 6, L $4 \mathrm{~mm}$ ). The ground and indifferent electrodes were placed over the cerebellum. Following electrode implantation, the entire assembly was fixed to the skull with a fast-curing dental acrylic.

After $1 \mathrm{~h}$, flexible wires were used to connect the electrodes to a preamplifier and EEG. Traces were recorded with a Pentusa system equipped with a $1-\mathrm{kHz}$ sample frequency and 1.6-400 Hz filter and saved on a computer hard drive. Control EEG was recorded for $10 \mathrm{~min}$ before PTZ (20 mg/kg) was injected. Recording continued for $15 \mathrm{~min}$ before 3 or $10 \mathrm{mg} / \mathrm{kg}$ of PHCCC or solvent $(1 \mathrm{ml} / \mathrm{kg}$ of $50 \%$ DMSO) was injected. A second $20 \mathrm{mg} / \mathrm{kg}$ dose of PTZ was administered $5 \mathrm{~min}$ later, and EEG recording continued for $60 \mathrm{~min}$ following the final treatment. Latency, number and the duration of the RMA were evaluated in 10-min sessions starting $5 \mathrm{~min}$ after the first PTZ injection with the exception of the interval when PHCCC was injected. The total and mean duration of episodes were calculated. In addition, the possible appearance of the minimal clonic seizures was assessed after the second PTZ dose.

\section{Cortical afterdischarges (ADs)}

Rat pups that were 12,18 and 25 days old were used in this experiment because younger rats do not reliably generate cortical ADs. Two stimulation electrodes were placed over the right sensorimotor cortex (AP +1 and -1; L $2.5 \mathrm{~mm}$ ) under ether anesthesia. Recording electrodes were placed as described above and connected to the Pentusa system (sample frequency $2 \mathrm{kHz}$ and filter $2-500 \mathrm{~Hz}$ ). ADs were elicited by $15-\mathrm{s}$ series of 1-ms biphasic rectangular pulses at $8-\mathrm{Hz}$ frequency using a constant current stimulator. Suprathreshold stimulations were repeated six times at $10-\mathrm{min}$ intervals and at $3-\mathrm{mA}$ intensity in the two older groups. A higher stimulation intensity (up to $5 \mathrm{~mA}$ ) was necessary in 12-day-old rats. EEG activity was recorded $20 \mathrm{~s}$ before stimulation, during stimulation and ADs and at least $60 \mathrm{~s}$ after the end of ADs. Five min after the first AD, PHCCC (3 or $10 \mathrm{mg} / \mathrm{kg}$ ) was injected intraperitoneally. Control animals received $50 \%$ DMSO in an amount corresponding to the higher dose of PHCCC (1 $\mathrm{ml} / \mathrm{kg})$. A number of animals exhibited transition of spike-and-wave ADs into the limbic type during the first control stimulation. This phenomenon was frequently observed in 25-day-old rats, and these animals were used to form an additional experimental group in which the effects of PHCCC on these mixed ADs were examined. AD duration and motor phenomena severity accompanying stimulation and ADs were evaluated.

\section{Statistics}

SigmaStat ${ }^{\circledR}$ for Windows Version 3.5 (SYSTAT, Inc.) was used for all analyses. Incidences of the different seizure types in Experiment 1 were compared using Fisher's exact test. The first step performed by Sigma Stat is evaluation of distribution of data and according to the results parametric (like in our case) or nonparametric tests are performed. Latencies and seizure severity were evaluated with one-way analysis of variance (ANOVA) and subsequent pairwise comparisons were performed with Holm-Sidak tests. 
Statistical evaluation of two experimental and one control groups at all ages tested in Experiments 2 and 3 was done using one-way repeated measurements ANOVA with subsequent pairwise comparison using Tukey's test. Possible differences between different drug doses in all age groups and the same doses in different age groups were evaluated by one-way ANOVAs and subsequent pairwise comparison was done with Holm-Sidak tests. Results were considered to be statistically significant at $\mathrm{p}<0.05$.

\section{Results}

\section{PTZ-induced convulsions}

Two types of convulsive seizures were elicited: minimal clonic seizures involving head and forelimb muscles with preserved righting ability in rats P18 and older and generalised tonic-clonic seizures (GTCS) in all age groups. GTCS began with a short phase of wild running (sometimes only a single jump) followed by a tonic phase $(5-15 \mathrm{~s})$ and a clonic phase lasting minutes (usually until the end of the 30-min observation period). Righting reflexes were lost during both tonic and clonic phases.
A

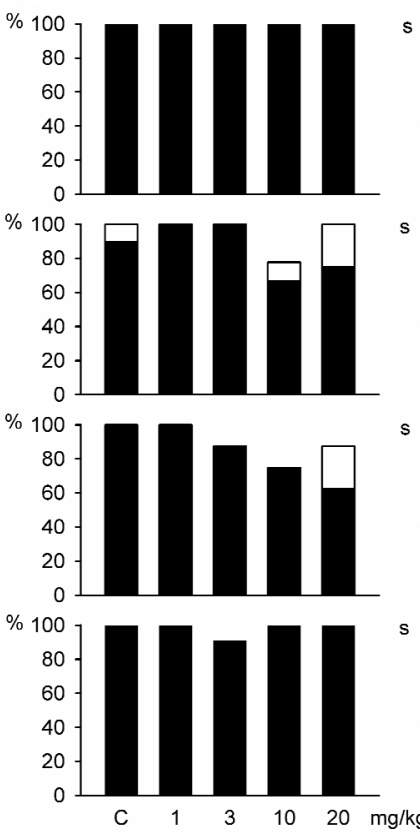

B

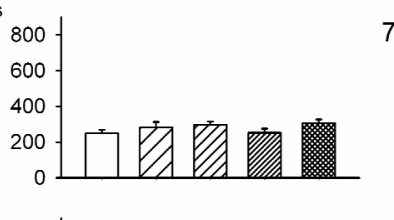

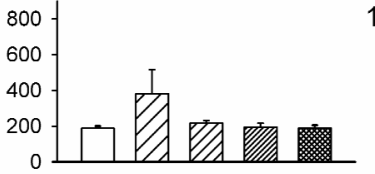
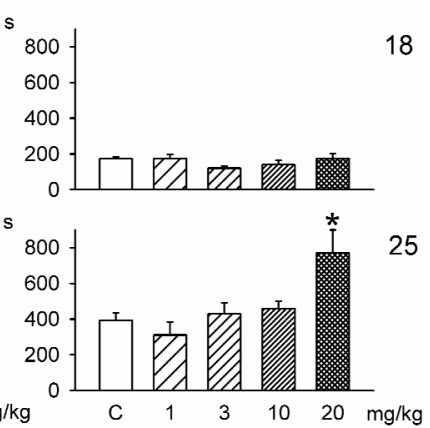

Fig. 1. Incidence (A) and latencies (B) of generalized tonicclonic seizures elicited by a high $(100 \mathrm{mg} / \mathrm{kg})$ dose of PTZ in four groups of rat pups (P7, P12, P18 and P25) pretreated with 1-, 3-, $10-$, and $20-\mathrm{mg} / \mathrm{kg}$ doses of PHCCC. Control animals received solvent only ( $50 \%$ DMSO).
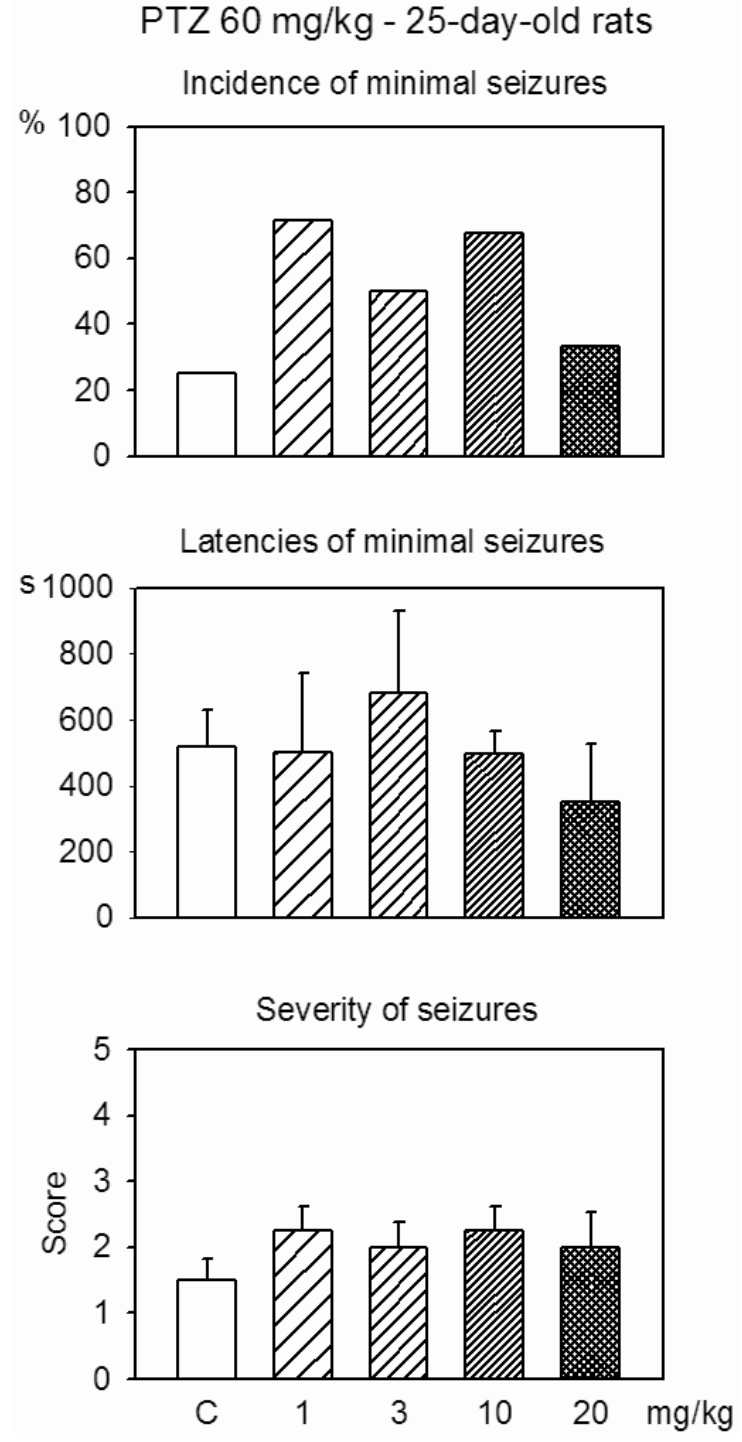

Fig. 2. Incidence, latency of minimal seizures and severity of seizures (mean + S.E.M.) induced by the $60-\mathrm{mg} / \mathrm{kg}$ dose of PTZ in P25 rats. Abscissae indicate individual doses of PHCCC. C represents control DMSO treated rats; ordinates from top to bottom - percentage of animals exhibiting minimal clonic seizures, latencies of these seizures in sec, score in five-point scale.

Minimal clonic seizures were observed in half of control 18-day-old rats and in all 25-day-old ones. Seizure latency and incidence were the same in rats pretreated with PHCCC. All control animals exhibited GTCS, with the exception of one 12-day-old rat showing only generalised clonic seizures without the tonic phase. Incidence of GTCS tended to decrease with an outlined effect on the tonic phase after the highest (10 and $20 \mathrm{mg} / \mathrm{kg}$ ) doses of PHCCC in P12 and P18 rats, but these changes were not statistically significant (Fig. 1A). GTCS incidence and pattern remained unchanged in 7- and 25-day-old rat pups after any PHCCC dose and after 1 - and $3-\mathrm{mg} / \mathrm{kg}$ doses in the remaining two age 
groups. GTCS latencies were significantly prolonged only after the highest dose of PHCCC (20 mg/kg) in P25 animals (Fig. 1B). The lower dose of PTZ $(60 \mathrm{mg} / \mathrm{kg})$, which was only administered in P25 animals, elicited minimal seizures in 2 out of 8 control rats. Pretreatment with the 1-, 3- and $10-\mathrm{mg} / \mathrm{kg}$ doses tended to increase the incidence of these seizures (to 70, 50, and $67 \%$ of animals, respectively). This increase did not reach the level of statistical significance. The $20-\mathrm{mg} / \mathrm{kg}$ dose of PHCCC had no effect on the incidence of seizures (Fig. 2).
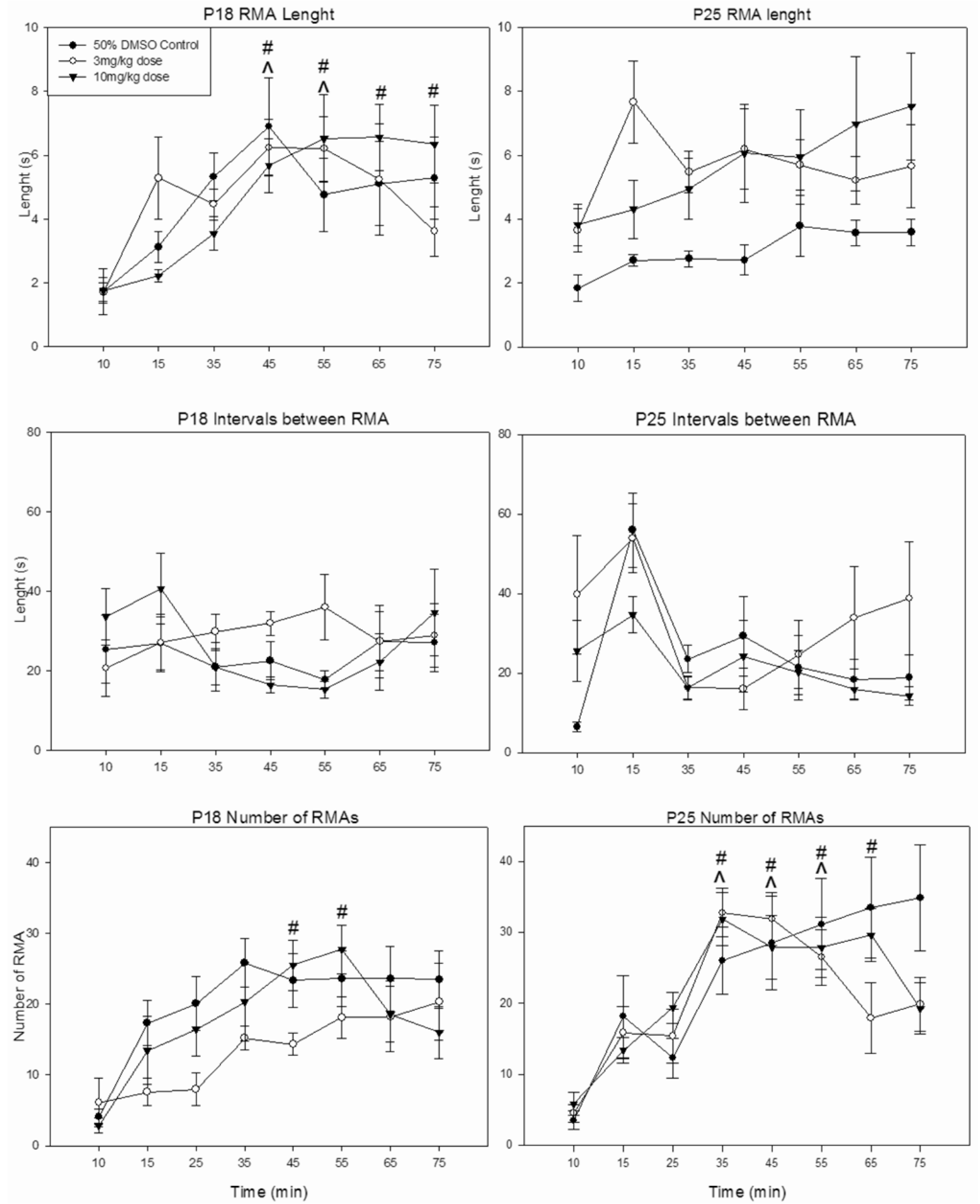

Fig. 3. Changes in neighbouring RMA episode intervals (upper graphs) and in RMA episode durations (lower graphs) in P18 (left panels) and P25 (right panels) rats registered during 85 min of EEG recording. Arrows demonstrate time of PTZ injections and the arrowhead denotes PHCCC administration. Asterisks denote significant differences compared with the first predrug interval, double crosses are for differences compared with the corresponding interval in the control group. 
PTZ-induced absence-like seizures

PTZ-induced absence-like seizures (rhythmic metrazol activity, RMA) were induced by the first PTZ injection in all animals. In the 18-day-old rats, DMSO and both doses of PHCCC prolonged RMA with a maximum $15 \mathrm{~min}$ after the second PTZ injection. No significant differences among the three groups were found. There were no marked peaks in the interval length between individual RMA episodes, and there was no significant difference between controls and PHCCC groups. There was, however, a significant difference between the two doses of PHCCC.

Twenty-five-day-old rat pups treated with the higher dose of PHCCC exhibited prolonged RMA episodes (Fig. 3 right panels, bottom graph). The difference between these animals and the control group was statistically significant at the two longest measured time sections after the second injection. Intervals between RMA episodes were markedly shortened in all three groups after the second injection of PTZ; this decrease was significant in both PHCCC groups, but the differences between the PHCCC groups and DMSO controls were not significant. The number of rhythmic episodes progressively increased in response to the 10 $\mathrm{mg} / \mathrm{kg}$ dose of PHCCC in the late phases of recording (Fig. 3).

\section{Cortical ADs}

The longer duration of the first ADs in 12-dayold control animals compared to the older groups was confirmed in the present set of experiments (Fig. 4). Control rats showed marked prolongation of cortical epileptic ADs with repeated stimulations in P18 $\left(5^{\text {th }}\right.$ and $6^{\text {th }} \mathrm{ADs}$ ) and, especially, in P12 rats ( $4^{\text {th }}$ to $\left.6^{\text {th }} \mathrm{ADs}\right)$. The oldest group did not show significant prolongation in spike-and-wave or in mixed ADs (Fig. 5).

There was a significant difference in the total duration of ADs started at the $4^{\text {th }} \mathrm{AD}$ in controls and at $3^{\text {rd }} \mathrm{AD}$ in the $3-\mathrm{mg} / \mathrm{kg}$ PHCCC group of 12-day-old rats. The $10-\mathrm{mg} / \mathrm{kg}$ dose of PHCCC did not potentiate prolonged $\mathrm{ADs}$ in this age group. Only the $10-\mathrm{mg} / \mathrm{kg}$ dose increased AD duration in 18-day-old rat pups; the first significant change was seen in the $4^{\text {th }}$ AD. The 25-day-old group exhibited significant prolongation only after PHCCC administration. The lower dose resulted in significantly longer $4^{\text {th }}$ and $5^{\text {th }}$ ADs and the $10-\mathrm{mg} / \mathrm{kg}$ dose in a longer $6^{\text {th }} \mathrm{AD}$. The $4^{\text {th }}$ and $5^{\text {th }} \mathrm{ADs}$ in the $10-\mathrm{mg} / \mathrm{kg}$ group and the $4^{\text {th }} \mathrm{AD}$ in the $3-\mathrm{mg} / \mathrm{kg}$ group of 25-day-old animals were significantly longer than corresponding ADs in the control rats.

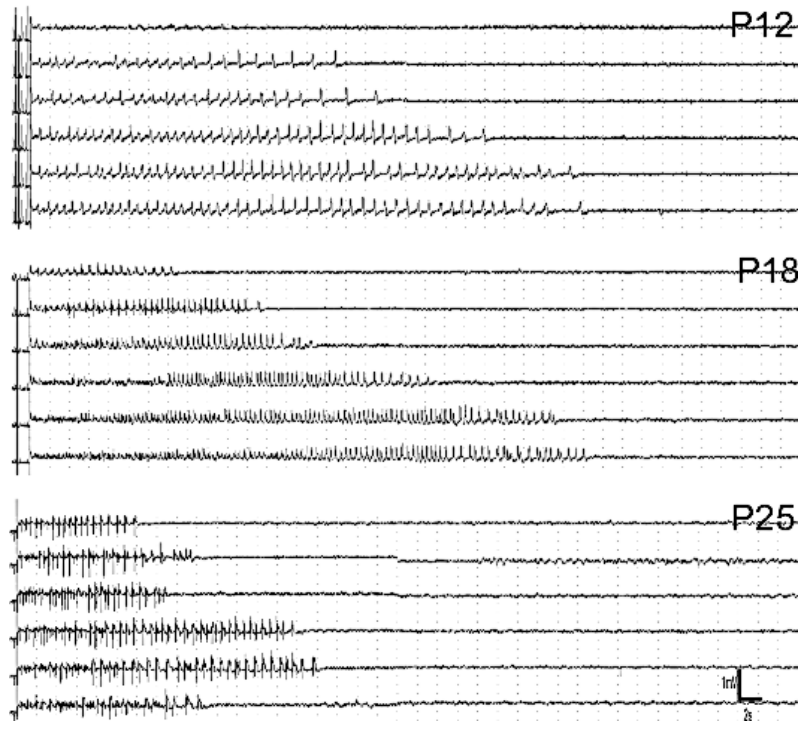

Fig. 4. EEG recording of the six subsequent cortical ADs (first to sixth row in each section) in P12, P18 and P25 rat pups after a $10-\mathrm{mg} / \mathrm{kg}$ dose of PHCCC. Time mark: $2 \mathrm{~s}$, amplitude calibration: $1 \mathrm{mV}$.

In the additional group of 25-day-old rats (Fig. 5B) with limbic ADs elicited by the first (control) stimulation, PHCCC administration resulted in longer durations of the $2^{\text {nd }}$ (the $3-\mathrm{mg} / \mathrm{kg}$ dose) and $3^{\text {rd }}$ (both 3- and 10-mg/kg doses) ADs compared with corresponding ADs in the DMSO-treated controls.

\section{Discussion}

In young $\mathrm{P} 25$ rats, we confirmed the in vivo activity of PHCCC - augmentation of rhythmic PTZ induced activity described in adult rats (Ngomba et al. 2008); a similar effect was not found in 18-day-old animals. No reciprocal effect on nonconvulsive and convulsive seizures was observed; PTZ-induced convulsions were not suppressed by PHCCC. In contrast, combination of PHCCC with the $60-\mathrm{mg} / \mathrm{kg}$ dose of PTZ in 25-day-old rats potentiated the convulsant effects of PTZ. PHCCC also exerted a moderate proconvulsant action on spike-and-wave ADs in all three age groups and on limbic ADs in $\mathrm{P} 25$ rats.

The in vivo seizure models used in the present study are generated in different brain structures. The model of absence seizures is characterised by episodes of bilaterally synchronous spike-and-wave discharges (SWDs) accompanied by minute motor phenomena, such as rhythmic jerks of vibrissae. SWDs are generated in cortico-thalamo-cortical network, where the RTN synchronises burst firing between glutamatergic thalamic relay neurons and neocortical principal neurons (Snead et 
A

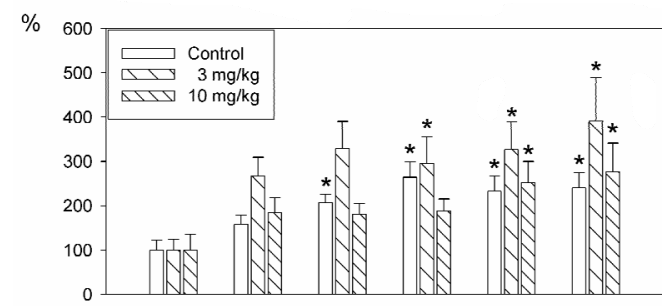

$\%$

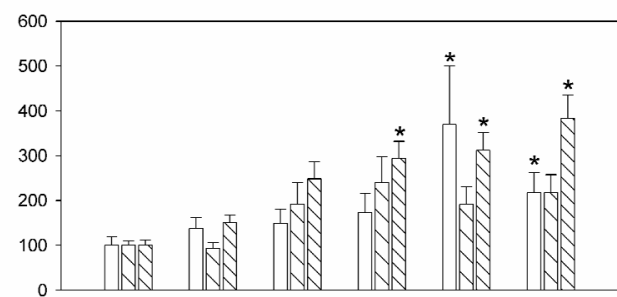

$\%$

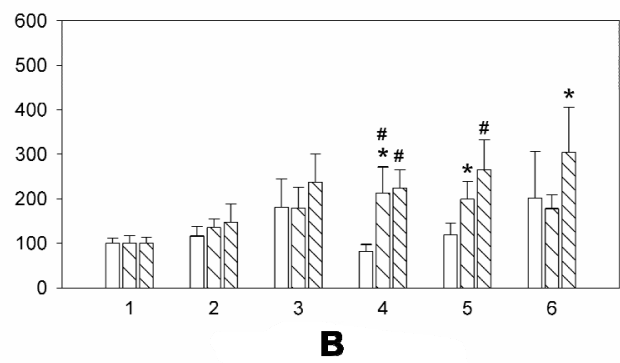

$\% 600$

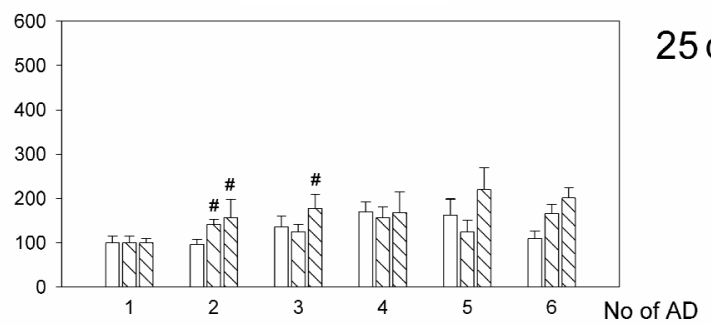

Fig. 5. Duration (mean + S.E.M.) of six subsequent cortical ADs (A) in P12, P18 and P25 rats, and duration of the second, limbic type of ADs observed in an additional group of P25 animals (B). Asterisks denote significant differences in comparison to the appropriate first (predrug) stimulation, double crosses show significant differences from corresponding $A D s$ in the control group.

al. 2000, Wang et al. 2005, Ngomba et al. 2008). High levels of mGluR4 mRNA and its proteins have been found in both human and rodent thalamic relay nuclei, but in the primary sensorimotor cortex, particularly in the outer cortical layers, mGluR4 protein levels are moderate or low (Ohishi et al. 1995, Corti et al. 2002). Thalamic mGluR4 receptors are mostly located presynaptically in cortical axon terminals. Furthermore, mGluR4 mRNA is not detectable in the RTN, suggesting that mGluR4 proteins found in RTN are from extrinsic inputs (Ohishi et al. 1995, Ngomba et al. 2008), probably thalamic relay nuclei. PHCCC aggravated models of absence seizures in adult mice and WAG/Rij rats (Snead et al. 2000, Ngomba et al. 2008). Presynaptic mGluR4 receptors in corticothalamic axons can reduce glutamate release in thalamic nuclei. This property influences GABAergic neurons in RTN and may increase synchronisation in the thalamocortical system (East et al. 1995, Salt and Eaton 1996, Snead et al. 2000, Ngomba et al. 2008). The role of mGluR4 in spike-and-wave rhythm was confirmed by gene targeting and pharmacological evaluation. The absence or inhibition of these receptors makes rodents resistant to absence epilepsy (Snead et al. 2000).

The role of mGluR4 in absence seizures was repeatedly demonstrated whereas its role in convulsive seizures remains unclear (Alexander and Godwin 2006). Two types of motor seizures induced by higher doses of PTZ have different generators. Minimal clonic seizures (a model of myoclonic seizures; see Löscher and Schmidt 1988) are generated in the basal forebrain, and their EEG pattern is formed by spike-and-wave rhythm, whereas generalised tonic-clonic seizures are of brainstem origin (Browning and Nelson 1986), and the spinal cord is also able to generate these generalised seizures (Mareš 2006). The EEG pattern of generalised tonic-clonic seizures varies, with rhythmic spikes being most common. The action of PHCCC was observed as an increased incidence of minimal seizures after the lower dose of PTZ; generalised tonic-clonic seizures remained mostly untouched.

Cortical epileptic ADs elicited by low-frequency stimulation of the sensorimotor cortex are another model of human myoclonic seizures (Mareš et al. 2002). These seizures of cortico-thalamo-cortical origin are also characterised by spike-and-wave EEG activity in 18- and 25-day-old animals. Twelve-day-old rat pups demonstrate only rhythmic sharp waves. In all age groups, cortical ADs are accompanied by clonic seizures, mostly of the contralateral forepaw with possible spreading to the hindlimbs. PHCCC potentiated these seizures, as well as their transition into the second, limbic type. PHCCC did not have any noticeable influence on motor phenomena evaluated during ADs, suggesting that this modulator does not interfere with the spread of epileptic activity into the motor system or with spinal cord motoneurons.

A commonality among models of seizures potentiated by PHCCC (episodes of spike-and-wave rhythm, minimal clonic seizures and cortical ADs) is their forebrain origin and the spike-and-wave rhythm apparent on EEG. This EEG rhythm is generated in corticothalamo-cortical circuit (Avazini et al. 1992). This rhythm is age dependent; the youngest rats in which this 
rhythm can be elicited are 18 days old (Mareš et al. 1982), an age that is in agreement with maturation of cortico-thalamic connection (Scheibel et al. 1976). The models differ in their motor counterparts: clonic seizures characteristic for minimal clonic seizures, as well as for cortical ADs, indicate the spread of activity into the motor system at least to the level of the cervical spinal cord. The individual jerks are synchronised with sharp EEG elements (Mareš et al. 2002). Rhythmic metrazol activity as a model of human absence seizures is characterised by minimal motor phenomena (minute jerks of vibrissae or ears). This finding signifies that in this case, epileptic activity spreads only to the nuclei of cranial nerves (n. trigeminus, n. facialis). The failure to affect generalised tonic-clonic seizures, as well as motor phenomena characteristic for minimal seizures and cortical ADs, can be explained by a lack of effect of PHCCC in the brainstem and spinal cord.

An important developmental difference was found in effects on minimal clonic seizures. They were potentiated in 25- but not in 18-day-old rats. Developmental changes in mGluR4 expression demonstrated weak labelling of mGluR4 mRNA at birth in all brain structures, except the thalamus, where a moderate signal can be observed. In brain structures involved in generating $\mathrm{ADs}$ and absence seizures (ventrobasal thalamus, RTN and layers IV-VI of cerebral cortex), the hybridisation signal is stable throughout development (Catania et al. 1994). Maturation of generator of the rhythmic activity as well as changes of pharmacodynamics might be a reason for the developmental difference. There are no data on pharmacokinetics of PHCCC but generally the catabolism of drugs matures during the third postnatal week in rats (Morselli 1983), therefore stronger effect should be expected in 18-day-old rats.

The second type of ADs, characterized by spread of epileptic activity into the limbic system, are better expressed in the older animals (P25), probably due to the maturation of polysynaptic connections between the thalamus and limbic structures (Bertram et al. 2001). In our experiments, PHCCC slightly influenced this type of seizure, but its action was observed more rapidly than in spike-and-wave ADs; afterdischarges were already significantly prolonged after the $2^{\text {nd }}$ and $3^{\text {rd }}$ stimulations.

A possible role of mGluR4 in the regulation of epileptic seizures is suggested by molecular biological data. Specifically, mGluR4 expression can be increased by convulsive seizures in the granule cells of the dentate gyrus in patients with temporal lobe epilepsy (TLE) or in fully symptomatic WAG/Rij rats (Lie et al. 2000, Ngomba et al. 2008). In addition, mGluR4 is encoded by a gene found on a locus close to one that is important for juvenile myoclonic epilepsy (Wong et al. 2001). This finding is in agreement with our observation that minimal clonic seizures (a possible model of myoclonic seizures) induced by a $60-\mathrm{mg} / \mathrm{kg}$ dose of PTZ were potentiated, and cortical ADs were augmented, by PHCCC administration.

Our results deny the possibility that mGluR4 activation may be a treatment for some forms of epilepsy (Marino et al. 2005). Rather, activating this receptor (at least in immature brain) may be dangerous in epileptic seizures that are generated in cerebral cortex or in the whole forebrain.

\section{Conflict of Interest}

There is no conflict of interest.

\section{Acknowledgements}

This study was supported by grant No. 200107 from the Grant Agency of Charles University, grant No. 305/06/1288 of the Grant Agency of the Czech Republic, research project LC554 of the Ministry of Education and research project AV0Z 50110509 of the Academy of Sciences of the Czech Republic.

\section{References}

ALEXANDER GM, GODWIN DW: Metabotropic glutamate receptors as a strategic target for the treatment of epilepsy. Epilepsy Res 71: 1-22, 2006.

AVANZINI G, DE CURTIS M, MARESCAUX C, PANZICA F, SPREAFICO R, VERGNES M: Role of the thalamic reticular nucleus in the generation of rhythmic thalamo-cortical activities subserving spike and waves. $J$ Neural Transm Suppl 35: 85-95, 1992.

BERTRAM EH, MANGAN PS, ZHANG D, SCOTT CA, WILLIAMSON JM: The midline thalamus: alterations and a potential role in limbic epilepsy. Epilepsia 42: 967-978, 2001. 
BROWNING RA, NELSON DK: Modification of electroshock and pentylenetetrazol seizure patterns in rats after precollicular transections. Exp Neurol 93: 546-556, 1986.

CATANIA MV, LANDWEHRMEYER GB, TESTA CM, STANDAERT DG, PENNEY JB JR, YOUNG AB: Metabotropic glutamate receptors are differentially regulated during development. Neuroscience 61: 481-495, 1994.

CHEN J, LARIONOV S, HOEROLD N, ULLMANN C, ELGER CE, SCHRAMM J, BECKER AJ: Expression analysis of metabotropic glutamate receptors I and III in mouse strains with different susceptibility to experimental temporal lobe epilepsy. Neurosci Lett 375: 192-197, 2005.

CONN PJ, PIN JP: Pharmacology and functions of metabotropic glutamate receptors. Annu Rev Pharmacol Toxicol 37: 205-237, 1997.

CORTI C, ALDEGHERI L, SOMOGYI P, FERRAGUTI F: Distribution and synaptic localisation of the metabotropic glutamate receptor 4 (mGluR4) in the rodent CNS. Neuroscience 110: 403-420, 2002.

CRYAN JF, KELLY PH, NEIJT HC, SANSIG G, FLOR PJ, VAN DER PUTTEN H: Antidepressant and anxiolytic-like effects in mice lacking the group III metabotropic glutamate receptor mGluR7. Eur J Neurosci 17: 2409-2417, 2003.

EAST SJ, HILL MP, BROTCHIE JM: Metabotropic glutamate receptor agonists inhibit endogenous glutamate release from rat striatal synaptosomes. Eur J Pharmacol 277: 117-121, 1995.

GOTTLIEB A, KEYDAR I, EPSTEIN HT: Rodent brain growth stages: an analytical review. Biol Neonate 32: 166$176,1977$.

HAAS KZ, SPERBER EF, MOSHE SL: Kindling in developing animals - expression of severe seizures and enhanced development of bilateral foci. Develop Brain Res 56: 275-280, 1990.

HOPKINS CR, LINDSLEY CW, NISWENDER CM: mGluR4-positive allosteric modulation as potential treatment for Parkinson's disease. Future Med Chem 1: 501-513, 2009.

KLAK K, PALUCHA A, BRANSKI P, SOWA M, PILC A: Combined administration of PHCCC, a positive allosteric modulator of mGlu4 receptors and ACPT-I, mGlu III receptor agonist evokes antidepressant-like effects in rats. Amino Acids 32: 169-172, 2007.

KOGO N, DALEZIOS Y, CAPOGNA M, FERRAGUTI F, SHIGEMOTO R, SOMOGYI P: Depression of GABAergic input to identified hippocampal neurons by group III metabotropic glutamate receptors in the rat. Eur $J$ Neurosci 19: 2727-2740, 2004.

LAVREYSEN H, DAUTZENBERG FM: Therapeutic potential of group III metabotropic glutamate receptors. Curr Med Chem 15: 671-684, 2008.

LIE AA, BECKER A, BEHLE K, BECK H, MALITSCHEK B, CONN PJ, KUHN R, NITSCH R, PLASCHKE M, SCHRAMM J, ELGER CE, WIESTLER OD, BLUMCKE I: Up-regulation of the metabotropic glutamate receptor mGluR4 in hippocampal neurons with reduced seizure vulnerability. Ann Neurol 47: 26-35, 2000.

LÖSCHER W, SCHMIDT D: Which animal models should be used in the search for new antiepileptic drugs? A proposal based on experimental and clinical considerations. Epilepsy Res 2: 145-181, 1988.

MAREŠ P: Ontogeny of ethosuximide action against two seizure models in rats is different. Life Sci 63: PL51-PL57, 1998.

MAREŠ P: Generalized seizures in rodents - only two patterns? In: Generalized Seizures. From Clinical Phenomenology to Underlying Systems and Networks. E HIRSCH, F ANDERMANN, P CHAUVEL, J ENGEL, F LOPES DA SILVA, H LUDERS (eds), John Libbey Eurotext, Montrouge, 2006, pp 70-72.

MAREŠ P, MAREŠOVÁ D, TROJAN S, FISCHER J: Ontogenetic development of rhythmic thalamo-cortical phenomena in the rat. Brain Res Bull 8: 765-769, 1982.

MAREŠ P, HAUGVICOVÁ R, KUBOVÁ H: Unequal development of thresholds for various phenomena induced by cortical stimulation in rats. Epilepsy Res 49: 35-43, 2002.

MARINO MJ, HESS JF, LIVERTON N: Targeting the metabotropic glutamate receptor mGluR4 for the treatment of diseases of the central nervous system. Curr Top Med Chem 5: 885-895, 2005.

MORSELLI PL: Development of physiological variables important for drug kinetics. In: Antiepileptic Drug Therapy in Pediatrics. PL MORSELli, CE PIPPENGER, J KIFFIN PENRY (eds), Raven Press, New York, 1983, pp 1-12. 
NGOMBA RT, FERRAGUTI F, BADURA A, CITRARO R, SANTOLINI I, BATTAGLIA G, BRUNO V, DE SARRO G, SIMONYI A, VAN LUIJTELAAR G, NICOLETTI F: Positive allosteric modulation of metabotropic glutamate 4 (mGlu4) receptors enhances spontaneous and evoked absence seizures. Neuropharmacology 54: 344-354, 2008.

OHISHI H, AKAZAWA C, SHIGEMOTO R, NAKANISHI S, MIZUNO N: Distributions of the mRNAs for L-2amino-4-phosphonobutyrate-sensitive metabotropic glutamate receptors, mGluR4 and mGluR7, in the rat brain. J Comp Neurol 360: 555-570, 1995.

PITSCH J, SCHOCH S, GUELER N, FLOR PJ, VAN DER PUTTEN H, BECKER AJ: Functional role of mGluR1 and mGluR4 in pilocarpine-induced temporal lobe epilepsy. Neurobiol Dis 26: 623-633, 2007.

SALT TE, EATON SA: Functions of ionotropic and metabotropic glutamate receptors in sensory transmission in the mammalian thalamus. Prog Neurobiol 48: 55-72, 1996.

SARICHELOU I, CAPPUCCIO I, FERRANTI F, MOSILLO P, CICERONI C, SALE P, STOCCHI F, BATTAGLIA G, NICOLETTI F, MELCHIORRI D: Metabotropic glutamate receptors regulate differentiation of embryonic stem cells into GABAergic neurons. Cell Death Differ 15: 700-707, 2008.

SCHEIBEL MA, DAVIES TL, SCHEIBEL AB: Ontogenetic development of somatosensory thalamus. I. Morphogenesis. Exp Neurol 51: 392-406, 1976.

SNEAD OC III, BANERJEE PK, BURNHAM M, HAMPSON D: Modulation of absence seizures by the GABA(A) receptor: a critical role for metabotropic glutamate receptor 4 (mGluR4). J Neurosci 20: 6218-6224, 2000.

STACHOWICZ K, CHOJNACKA-WOJCIK E, KLAK K, PILC A: Anxiolytic-like effects of group III mGlu receptor ligands in the hippocampus involve GABAA signaling. Pharmacol Rep 58: 820-826, 2006.

SZCZUROWSKA E, MAREŠ P: Controversial action of positive modulator of subtype 7 of metabotropic glutamate receptors AMN082 on cortical epileptic afterdischarges in immature rats. Eur J Pharmacol 623: 37-40, 2009.

VELÍŠEK L, KUBOVÁ H, POHL M, STAŇKOVÁ L, MAREŠ P, SCHICKEROVÁ R: Pentylenetetrazol-induced seizures in rats: an ontogenetic study. N-S Arch Pharmacol 346: 588-591, 1992.

VERGNES M, BOEHRER A, SIMLER S, BERNASCONI R, MARESCAUX C: Opposite effects of GABAB receptor antagonists on absences and convulsive seizures. Eur J Pharmacol 332: 245-255, 1997.

WANG X, AL J, HAMPSON DR, SNEAD OC III: Altered glutamate and GABA release within thalamocortical circuitry in metabotropic glutamate receptor 4 knockout mice. Neuroscience 134: 1195-1203, 2005.

WONG CG-T, SCHERER SW, SNEAD OC III, HAMPSON DR: Localization of the human mGluR4 gene within an epilepsy susceptibility locus. Molec Brain Res 87: 109-116, 2001. 